\title{
La ensayística cultural de Jorge Mañach desde la teoría del arte y los estudios culturales latinoamericanos
}

\section{Jorge Mañach's Cultural Essays from Theory of the Art and Latin American Cultural Studies}

\author{
Maricel Coloma Rizo \\ Universidad de Ciencias Pedagógicas Frank País García, Cuba \\ mcoloma@ucp.sc.rimed.cu
}

\section{Resumen}

Jorge Mañach (1898-1961) fue uno de los más importantes intelectuales cubanos de la primera mitad del siglo XX y sus ensayos culturales alcanzaron notoriedad continental. Si bien numerosos autores coinciden en identificarlo por estos elementos, lo cierto es que aún no integra el índice de autores de América Latina que se reconocen dentro de la tradición de los Estudios Culturales latinoamericanos. Por otra parte, tampoco se ha reconocido su contribución al desarrollo de la teoría del arte, debido a que persiste la idea de que esta disciplina tiene aún limitaciones en su desarrollo epistémico en nuestra región. Este trabajo propone reflexionar sobre la ensayística cultural de Jorge Mañach Robato, precisamente a partir de su relación con los estudios culturales latinoamericanos y su aporte a la teoría del arte en Cuba.

Palabras clave: Jorge Mañach, teoría del arte, Estudios Culturales latinoamericanos, ensayo.

\begin{abstract}
Jorge Mañach (1898-1961) was one of the most important Cuban intellectuals in the first half of the XXth century and his cultural essays reached continental fame. Although, numerous authors agree in identify him for these elements, the certain thing is that he doesn't still integrate the index of authors from Latin America that are recognized inside the tradition of the Latin American Cultural Studies. On the other hand, their contribution has neither been recognized to the development of the theory of the art, because it persists the idea that this discipline still has limitations in its epistemic development in our region. This paper pretends to meditate on Jorge Mañach's cultural essays, starting from its relationship with the Latin American Cultural Studies and its contribution to the theory of the art in Cuba.
\end{abstract}

Keywords: Jorge Mañach, Theory of the Art, Latin American Cultural Studies, Essay. 
La validez y efectiva existencia de una teoría del arte y la cultura artística en Latinoamérica, viene desentrañándose desde hace algún tiempo. Aunque sus planteamientos iniciales aparecen alrededor de la década del setenta con obras de Roberto Fernández Retamar y Pedro Mir, en 1993 un teórico del posmodernismo como Fredric Jameson, en su "Introducción" a un número especial de $S A Q$, apuntaba los que a su juicio, constituían los cuatro problemas fundamentales de la teoría del arte que aún no habían encontrado solución en nuestro continente y su desventajosa situación con respecto a los países centrales. Este número especial era el resultado de la Primera Conferencia Internacional de las Artes Visuales que tuvo lugar en febrero de 1992, en Caracas, Venezuela. Jameson iniciaba:

This special issue of SAQ dramatizes the intersection between four fundamental themes: the claims of theory today, the relative underdevelopment of theory in the visual arts, the unequal cultural relationships between third and first worlds, and the momentous changes and transformations that the new thing call postmodernism has introduced into all three preceding areas $(417)^{1}$

En efecto, justo en este momento en que el autor introduce los ensayos de latinoamericanos como Néstor García Canclini y Nelly Richard (y otros como Geeta Kapur de la India), estos son los principales problemas que presentaba la teoría de las artes visuales en su relación con los centros hegemónicos de poder, en donde también tienen lugar los grandes sistemas de reflexión sobre el arte que hasta hoy reconocemos. Restan problemas aún sin resolver: la desigualdad en la socialización del conocimiento científico, verticalizada por la relación centro/periferia y el acceso a las tecnologías, además del necesario reclamo de una teoría de las artes visuales.

En esa misma edición, Néstor García Canclini iniciaba su ensayo con una pregunta medular - en su momento- que hasta hoy, con autores como Juan Acha, Adolfo Colombres y el propio Canclini ya va obteniendo respuesta:

What can Latin American aesthetics and art contribute to the contemporary theory of the visual arts? Various difficulties arise in responding to this question. The first that in the theory of art, as in other theories, the paradigms that have not already fallen are wavering. Therefore, perhaps, the most reasonable contribution that we can propose is not a collection of our own theses, but reformulation of the questions. (423) ${ }^{2}$

1 Este número especial de SAQ dramatiza la intersección entre cuatro temas fundamentales: los reclamos de hoy por una teoría, el relativo subdesarrollo de la teoría en las artes visuales, la desigual relación cultural entre países del tercer y el primer mundos, y los trascendentales cambios y transformaciones que algo nuevo como el posmodernismo ha introducido en las tres áreas anteriores. (Traducción de la autora)

2 ¿Cómo pueden la estética y el arte latinoamericanos contribuir a la teoría de las artes visuales contemporáneas? Varias dificultades se presentan para responder a esta interrogante. La primera es que en la teoría del arte, como en otras teorías, los paradigmas que no se han derrumbado, están vacilantes. Por esto tal vez, la contribución más razonable que podamos proponer, no es una colección de nuestras propias tesis, sino una reformulación de las preguntas. (Traducción de la autora) 
Reformular las preguntas es claramente el camino más simple para la evaluación de una probable teoría de la cultura artística en Latinoamérica. Tal reformulación de las preguntas, no deberá realizarse sin desconocer la tradición del continente de reflexionar sobre sí mismo y sobre aspectos de marcado interés cultural, prácticamente desde que se iniciara su incorporación al mapa geográfico del mundo, desde fines del siglo XV e inicios del XVI ${ }^{3}$.

Autores como Roberto Fernández Retamar y Pedro Mir (1979), Néstor García Canclini (1984), Gerardo Mosquera (1999), Beatriz Sarlo (2002), Nelly Richard (2002) y Adolfo Colombres (2004), desde sus diferentes perspectivas, reconocen que una de las principales limitaciones está en el apego miope a un entramado crítico y teórico que se gesta desde los centros hegemónicos europeos y norteamericanos. Estos centros (que constituyen una red académica, museológica, editorial, etc.), desconocen los estatutos de identidad, producción, circulación y consumo del arte y la literatura latinoamericanos ${ }^{4}$.

En este sentido, una de las preguntas a las que podría haberse referido Canclini, ha sido formulada por Nelly Richard: “¿Cómo hablar lo propio si el repertorio es de nombres prestados?" (Campos cruzados 176). Pues resulta que en este apego miope a las tradiciones estéticas del pensamiento europeo (y eurocentrista), hemos desarrollado una tendencia a no reconocer, en la obra de ciertos intelectuales de nuestro continente, presupuestos teóricos que, desde nuestro propio horizonte semántico, reflejan de otra manera nuestro campo artístico otro. Para el caso cubano, uno de los autores fundamentales de la primera mitad del siglo XX es sin dudas, Jorge Mañach (1898-1961).

Si bien es cierto que abandonó el país por última vez en $1960^{5}$, Jorge Mañach Robato fue uno de los líderes del Minorismo, grupo cubano de la década del veinte que promovió la renovación en lo artístico y en lo cívico; también fue fundador, en 1927, de la Revista de Avance y miembro, desde 1931, del ABC, en el cual participó como co-autor de su manifiesto-programa.

Al margen de estas observaciones, incuestionablemente Mañach alcanzó notoriedad y reconocimiento continental por su obra ensayística y llegó a convertirse en uno de los escritores más importantes del género en su época. Aunque lo más lúcido de su producción está sin lugar a dudas, en el ensayismo (Amalia V. de la Torre, 1978; Andrés Valdespino, 1979; Jorge Luis Arcos, 1999; Rafael Rojas, 2008), su obra literaria abarcó múltiples géneros: el teatro, la novela, la crítica literaria y

3 Raúl Bueno, en Promesa y descontento de la modernidad propone que la reflexión latinoamericana sobre la cultura, al menos en su intención de describir y registrar la cultura del "otro", se inició con los llamados viajes de descubrimiento.

4 En este sentido, la propia enunciación disciplinar enfrenta difíciles derroteros pues lo que se reconoce como Teoría del Arte (o de las artes visuales) en el mapa curricular universitario de nuestro país, se denomina Teoría de la Cultura Artística. Para el presente trabajo se emplearán ambos términos indistintamente.

5 También por discrepancias con los gobiernos de turno, Jorge Mañach se había exiliado del país en dos ocasiones anteriormente: en 1933 y 1953. 
de artes visuales, el periodismo, etc. Publicó, entre muchos títulos Para una filosofía de la vida y otros ensayos en 1951, también Dewey y el pensamiento americano en 1959, aunque uno de los más conocidos es Martí, el apóstol (1933). Ante una vida y obra con tales aristas, tal vez por esto en 2003, Duanel Díaz intentara con el texto Mañach o la república:

tomar la obra de Mañach, sobre todo sus trabajos más vinculados a la situación cubana, como vías de acceso que dan a ciertas zonas de la República. En vez de aplanarlo todo con el peso de la apología, es preciso volver a las polémicas. En vez de meter el choteo en una cazuela con las parodias cubanas de Piñera y las exuberantes comidas criollas de Lezama, es preciso iluminar las divergencias, los conflictos, los costurones. (43-44)

No obstante, las polémicas, los conflictos y costurones nos dan referentes concéntricos de un Mañach siempre en relación con los intelectuales de lo que él mismo denominara "su más inmediata circunstancia", alejándonos de una visión más estrictamente científica que permita revelar sus aportes a la teoría del arte y al mismo tiempo, confirmar su pertenencia a la tradición de los estudios culturales latinoamericanos.

Sobre esto mismo, no se considera que Jorge Mañach en efecto supere tal contradicción, que ha lastrado al pensamiento latinoamericano: la persistente tara de analizar, describir, interpretar obras y procesos relacionados con el campo artístico, cuando el horizonte semántico funciona también como una prisión (Fernández Retamar, 1979a, 1979b; García Canclini, 1989) .

Es precisamente a esto a lo que se refería Jameson cuando enunciaba el "relativo desarrollo de la teoría en las artes visuales". En el caso de estas últimas, algunos de los primeros intentos por plantear teóricamente este aspecto, aparecen concentrados en la década del ochenta, con trabajos de Néstor García Canclini, Juan Acha, Ticio Escobar y los autores mencionados anteriormente. Estos trabajos partían de una reflexión crítica directamente derivada del análisis de nuestras prácticas artísticas.

Queda claro que una teoría de nuestras prácticas artísticas no necesariamente se constituye en un "cuerpo de reflexiones completo, acabado e indiscutible" (Bueno $28)^{7}$. Un aspecto fundamental que sirve para refrendar esta idea, y que está presente en la obra de Jorge Mañach, es su marcada tendencia al electivismo. Aquella apropiación

6 En los últimos treinta años, encontramos que los nombres de Leopoldo Zea con el tema de la conciencia latinoamericana, Néstor García Canclini con su definición de las actuales culturas híbridas latinoamericanas, Ticio Escobar con la teoría de la especificidad del mito y el rito entre los indígenas latinoamericanos, Juan Acha con la idea de un pensamiento visual independiente para nuestro continente, o Adolfo Colombres con su teoría transcultural del arte, pueden ser inscritos dentro de la historia y evolución epistemológica de la teoría de la cultura artística a nivel mundial.

7 La propia reflexión teórica sobre el arte europeo, del cual se desgaja, es accidentada, plagada de constantes superposiciones y polémicas -algunas de ellas aún sin resolver- a partir de un planteamiento epistémico también en constante cambio. La relación entre ambas - la teoría del arte europea y latinoamericana- no deberá abordarse desde un esquema de dominación, en el que, de manera regular, se tomen categorías, principios, tendencias y/o modelos para su aplicabilidad a nuestra realidad artística. Antes bien, se valorará la creatividad con que han sido tomadas estas categorías, principios, tendencias y/o modelos. 
creativa de los modelos, tendencias y corrientes de los que este autor echa mano para sostener sus disquisiciones sobre la cultura cubana.

Sobre esto mismo, Rigoberto Segreo ha señalado que este autor puede ser considerado como un historiador de la cultura con un método de análisis sustentado en el idealismo antropológico. Aunque sostenemos la idea de que el centro de la perspectiva mañachiana tiene firmes raíces en la clave electiva propia del pensamiento decimonónico cubano.

Esta problemática se complejiza si tomamos en consideración el actual debate, en el que Alicia Ríos y Raúl Bueno proponen desconocer la clasificación en un trazado disciplinar, que reduciría los análisis de las obras de intelectuales latinoamericanos a una suerte de "camisa de fuerza", cuando en rigor, sus producciones trascienden los marcos epistémicos de una ciencia y/o disciplina de estudios. No es ocioso recordar que es en extremo difícil clasificar una obra como la de Fernando Ortiz, no solamente -como pudiera suponerse - por el volumen de la misma, sino por la transdisciplinariedad, apertura de campos y multiplicidad de objetos de estudio que la caracterizan.

Sobre este particular, en el año 2002, Daniel Mato coordinó la edición del volumen Estudios y otras prácticas latinoamericanas en cultura y poder, en el que participaron, junto a otros, el propio Mato y algunos de los autores mencionados anteriormente. Este texto era el resultado de la presentación de ponencias en la Tercera Reunión del Grupo de Trabajo "Cultura y Poder" del Consejo Latinoamericano de Ciencias Sociales (CLACSO) en 2001. En el mismo, los autores coinciden en que los estudios culturales en América anteceden en fecha y densidad a la escuela de Birmingham, pero por sus peculiaridades - siempre en función de su contexto más dinámico y complejo debido a la herencia colonial y actual situación periférica- deberían denominarse "estudios en cultura y poder", de modo que se garantiza, desde su nomenclatura, la diferenciación con respecto a los de origen londinense ${ }^{8}$.

Se impone un aparte. George Yúdice en El recurso de la cultura. Usos de la cultura en la era global (2006), aunque se refiere a la manera en que se enfrentó la globalización desde los Estudios Culturales, para este autor, los iniciadores británicos de los Cultural Studies tuvieron uno de sus mayores aportes, en la no visualización de la cultura como centro de la oposición binaria barbarie/civilización, en la que la cultura sería el non plus ultra del modo civilizado", sino "como estrategias y medios por

8 La Escuela de Birmingham, cuya apertura se ubica en 1964 con el Centre for Contemporary Cultural Studies, se reconoce como la iniciadora de los estudios culturales, precisamente a partir de la llamada Teoría Crítica con autores como Richard Hoggart, Stuart Hall y Raymond Williams

9 Esta noción de cultura como indicador de un nivel superior dentro de la civilización, sí acompañó a algunos intelectuales y estudiosos de la República. En Urgencias culturales de Cuba, Ortiz llama a una “...renovación efectiva del concepto de la cultura, la de su orientación, la de su instrumental, la de su intensidad, la de sus articulaciones y la de su función democrática (...) Y es así como debemos ir entendiendo, practicando y organizando la cultura cubana si esta ha de realizar plenamente su función; no como meras realizaciones individuales sino como un sistema de la integración colectiva y de la superación nacional.” (Ortiz, 1944: 130 y 131). También Mañach, en La Nación y la formación histórica significa: “...Cultura significa, por un lado, diversificación de los modos de existencia posibles; por el lado subjetivo, supone aptitudes para el discernimiento, para la selección, para la crítica." (Mañach, 1944: 27) 
los cuales el lenguaje y los valores de las diferentes clases sociales reflejan un sentido particular de comunidad, y que se instala (...) en el lugar que le abre ese complejo campo de fuerzas llamado nación" (99).

Igualmente, este autor afirma que los Cultural Studies, cuya génesis europea se ubica en la década del cincuenta y su institucionalización, una década más tarde, con el Birmingham Centre for Contemporary Cultural Studies; se centraron en análisis como los apuntados anteriormente, pero desde el más inmediato entorno nacional. Afirma también, que esta idea se replicó, bien desde los estudios de comunicaciones en Estados Unidos, o bien desde enfoques antropológicos y sociológicos en América Latina, aunque todos desde la idea de los nacionalismos.

Junto con Yúdice, otros autores también coinciden en que la concepción más extendida de los Estudios Culturales, significó una profunda renovación metodológica cuya emergencia es relativamente contemporánea, y que quiebran los antiguos límites de las tradicionales disciplinas académicas de estudio (Daniel Mato, Ana del Sarto, Alicia Ríos, Nelly Richard et al, 2003) Los iniciadores de esta corriente (Escuela de Birmingham, estudios culturales norteamericanos), afirman que, tal ruptura de barreras epistemológicas se inicia precisamente a partir de su designación británica.

Sin embargo en el texto coordinado por Daniel Mato, la investigadora Alicia Ríos sostenía que, grosso modo, los denominados estudios culturales latinoamericanos podrían definirse como un campo que se articuló a partir de la tradición crítica latinoamericana y que se ha mantenido en diálogo - desde su propia génesis- con las corrientes y escuelas de pensamiento estadounidenses y europeas. Sugiere también que una probable definición de este campo no deberá emprenderse a partir del análisis de ciertas temáticas, sino por "el acercamiento metodológico y epistemológico a dichos temas" (247).

Se precisa, cada vez más de investigaciones que revelen el modo en que se ha concebido, desde los estudios culturales, una definición teórica del arte. En este sentido, el texto Historia y estilo, de Jorge Mañach, resulta interesante, debido a que muestra una comprensión de la evolución de los estilos a partir de las particulares circunstancias históricas en el caso de Cuba.

La autora de la presente investigación coincide con Ríos en que el también llamado "campo emergente" no significa de un solo lado la ruptura epistémica con lo que se había hecho antes, más que ello, propone que los estudios culturales latinoamericanos - atendiendo a las características fundamentales- se pudieran definir también a partir del devenir continuo y sistemático del pensamiento crítico latinoamericano:

Me interesa mostrar cómo la larga tradición del ensayo de ideas en América Latina está atravesada, a lo largo de su historia, por ciertos ejes temáticos y posiciones enunciativas que marcan todavía hoy muchas de las preocupaciones de su pensamiento crítico: la cuestión nacional y continental [...] el papel de los intelectuales y las instituciones en sus formaciones discursivas y en las prácticas sociales, culturales y políticas. (Ríos 248) 
Particularmente en el artículo antes citado, aunque con una acertada visión del carácter transdisciplinar de los estudios culturales latinoamericanos, Alicia Ríos reconoce autores de sobrada trascendencia continental en una suerte de árbol genealógico de los estudios culturales latinoamericanos: Andrés Bello, José Martí, José Enrique Rodó, Pedro Henríquez Ureña, José Carlos Mariátegui, Fernando Ortiz hasta llegar a Roberto Fernández Retamar y Ángel Rama.

Las necesarias síntesis derivadas de publicaciones de este tipo, generalmente limitan la amplitud de ejemplos que los autores ponen a disposición de sus lectores; sin embargo, resulta significativa la ausencia de otros intelectuales cubanos de marcada proyección continental como es el caso, por ejemplo de Jorge Mañach.

También como parte de este volumen, George Yúdice, en su ensayo Contrapunteo estadounidense/latinoamericano de los estudios culturales apunta:

Si los Cultural Studies [SIC] se encuentran bien institucionalizados en Estados Unidos, en América Latina no sólo no ha existido esta etiqueta, sino que los "estudios en cultura y poder", como los llama Daniel Mato, se encuentran diseminados en espacios muy diferentes: universidades, periódicos, revistas, estaciones de radio, organizaciones civiles, grupos feministas, museos, municipalidades e incluso intelectuales independientes. De ahí la multidisciplinariedad, que se encuentra ya en el ensayo intelectual novecentista (Saco, Bello, Sarmiento, Martí, etc.) (340)

La autora coincide con Yúdice en la evidente tendencia a la multidisciplinariedad de los autores que menciona como antecedentes en el pensamiento decimonónico latinoamericano, aspecto medular para definir los límites temporales de los estudios culturales en Latinoamérica. No coincide, en cambio, en que tal multidisciplinariedad sea una consecuencia de la diseminación en diversificados espacios (universidades, periódicos, revistas...), sino a la inversa: el empleo de tales espacios, es precisamente la resultante, por un lado, de enfoques abiertos y plurales, y por otro, del empleo del ensayo como soporte fundamental de sus reflexiones ${ }^{10}$.

Precisamente es el total de la obra de Jorge Mañach, una suerte de confirmación de la idea de Yúdice. Los temas abordados en los artículos en periódicos y revistas de larga tirada como Diario de la Marina o Bohemia, su concepción de la Universidad del Aire, los abordados en sus ensayos de entrada a la Academia de Historia de Cuba y a la de Artes y Letras, rebasan constantemente los limitados (y limitantes) marcos disciplinares y, en efecto, coincide con la dispersión editorial apuntada por Yúdice.

No es por otra parte ocioso, notar que: "el intelectual juega un papel muy distinto en América Latina que en Estados Unidos, operando como sustituto de la sociedad civil -habla o representa al "pueblo"- a la misma vez que sirve de parachoques entre

10 Este género, de sólida gravitación tradicional en el continente latinoamericano, tiene, como ha apuntado José Luis Gómez-Martínez, un marcado carácter dialogal que lo caracteriza. 
ese pueblo y el Estado" (Yúdice, Contrapunteo 340), idea a la que significativamente también contribuye la propia vida de Mañach, quien desde la década del veinte del siglo pasado se hizo notar en la res publica cubana.

Desde otra perspectiva, en relación con los estudios culturales latinoamericanos, Nelly Richard asegura que tal tradición se viene desvaneciendo, precisamente, a partir de la hegemonía de los estudios culturales nacidos de la tradición angloparlante. Lo que supone, de facto, la confirmación de que la datación histórica de los estudios culturales del Nuevo Continente, antecede a los que ostentan partida de nacimiento británica, aunque la emergencia y colocación de los últimos haya desplazado a los de origen periférico. En opinión de la Richard, tal desplazamiento se debe a que la relación centro/periferia, está sometida a la "dictadura" formal de las revistas y centros de estudio e investigación, que operan bajo bien estrictos criterios de redacción y exposición de resultados científicos. A su juicio, esto lastra profundamente la tradicional reflexión latinoamericana y su forma de expresión por excelencia: el ensayo.

En este sentido, como Alicia Ríos y Raúl Bueno, también Nelly Richard pone especial énfasis en la presente validez o inoperatividad de los poco flexibles marcos disciplinares académicos, desde la idea de nuevas aperturas que se orientan hacia la inter, trans y multi disciplinariedad, aspecto que podría ser rastreado en numerosos textos anteriores incluso al siglo XX (Richard, Campos cruzados). Sobre este particular, son fácilmente reconocibles en numerosos autores de América Latina -también de la primera mitad del siglo XX - referentes que, desde el podio de un género de sólida construcción en el continente -el ensayo- se acercaron, no sin conflictos, a objetos de estudio que constantemente eludían el estrecho marco de una única disciplina de estudios ${ }^{11}$.

No se debe olvidar que es precisamente en la primera mitad del siglo XX cuando ocurre una importante renovación de los estudios académicos, en función de los trazados disciplinares que intentaban mantener como inamovibles los campos y objetos de estudio de cada uno. Si se compara el resultado de esta renovación, que pretendía rearticular los planes de estudios en las academias universitarias, para avanzar sobre el proyecto decimonónico de herencia enciclopedista, en función de estudios con mayor grado de especialización, se revela con facilidad el marcado carácter transdisciplinar del objeto de estudio aquí planteado.

Se impone como criterio de la autora que la obra del intelectual aquí analizada, aún cuando se parte de la exigencia metodológica del análisis de una obra -Historia y estilo- no se ubica con facilidad dentro de alguna específica disciplina académica de estudios (literatura, estética, crítica, historia, artes), sin que sus consideraciones mantengan límites flexibles, cuando no permeables, con otras disciplinas en el orden

11 En general, se puede afirmar que el caso paradigmático en Cuba, lo constituye la obra de Fernando Ortiz, que transita desde lo jurídico, lo sociológico, lo antropológico, lo artístico, lo psicológico...y podríamos continuar enumerando campos de erudición. Tal y como afirma Yúdice en el ensayo citado: "Piénsese, por ejemplo, en el contrapunteo de economía, politología, antropología e historia en la obra de Ortiz." (341) 
metodológico o teórico propiamente dicho. De ahí que resulta más evidente la necesidad de acercarse a la misma desde una perspectiva que considere sus antecedentes conceptuales y al mismo tiempo, respete su pertenencia a la tradición del pensamiento culturalista latinoamericano.

Esto último resulta medular en la obra de Jorge Mañach, en tanto su posición como intelectual puede ser valorada en relación sincrónica con sus contemporáneos, tanto cubanos como europeos y norteamericanos, sin olvidarnos de la dificultad que supone "encasillarlo" en alguna disciplina académica de estudios -además de la Filosofía y la Historia de la Filosofía - sin que su producción pueda ser abordada desde otras perspectivas e intereses ${ }^{12}$.

En otro revelador texto de Nelly Richard ${ }^{13}$ en el que se valoran las condiciones históricas en las que se dan las relaciones entre los llamados países centrales y periféricos, en cuanto al conocimiento y la reflexión sobre la cultura, esta autora ha afirmado que en la actualidad, más allá de los procesos de desterritorialización del capital económico y de la interplanetarización económica, la globalización también se expresa en la producción de saberes y teorías. Su estructura se configura en una red transnacional de instituciones y de conocimientos que administra recursos para la circulación de las ideas y programa las agendas del debate intelectual. Es allí donde los campos universitarios y académicos están marcados por las asimetrías entre lo global y lo local.

En este panorama, los estudios culturales, así como antes venían desde Europa, hoy se exportan desde la red metropolitana centrada en los Estados Unidos. En relación a esto, existen muchos debates en América sobre los riesgos que suponen la transferencia y reproducción periféricas de sus modelos de estudio que en rigor, parten de un proyecto cuya circunstancia resulta ajena a la tradición latinoamericana.

Esto implica que la dominante académica norteamericana/europea otorga legitimidad institucional a los términos de debate que ella misma clasifica y organiza de acuerdo a sus jerarquías conceptuales y políticas institucionales. Si bien es cierto que la multi-dimensionalidad y la heterogeneidad de lo local latinoamericano (países "colocados" en la periferia cuya producción académica e intelectual resulta siempre "local") es constantemente homogeneizada por el aparato de traducción académica que no toma en cuenta la pluralidad de discursos y contextos de enunciación.

"Preguntémonos qué ocurre cuando hasta la metáfora del descentramiento es administrada y rentabilizada por un discurso que sigue dotado de la prerrogativa de decidir las claves que le darán renombre y distintividad a esta nueva crisis de títulos y dominios" (Richard, La estratificación 58). Esta autora considera que la reflexión de

12 En este sentido, las disciplinas (sociales, humanísticas) funcionan también para definir y revisar, desde lo epistémico, el comportamiento de la relación objeto/conocimiento. Pero sobre todo, las disciplinas resultan formas de legitimación del campus académico, expresadas en saberes que se consagran a través de diversas estrategias que soportan la autoridad de ese saber.

13 Disponible en http://www.bibliotecavirtual.clacso.org.ar. 
y sobre los estudios culturales no debe quedar limitada entre los polos de la asimetría Norte/Sur o centro/periferia, sino precisamente a partir de los temas planteados, los enfoques y ángulos de encuadre de los mismos, además de los métodos y teorías elegidas. Tómese en consideración que la relación entre ubicaciones geoculturales, localizaciones institucionales y tipos de discurso no es una relación preestablecid a y fija, sino una relación de suyo construible y rearticulable.

Precisamente, una de las problemáticas fundamentales a la que se enfrentan los historiadores del arte en nuestra región, estriba en el intento de explicar, mediante estos constructos teóricos enunciados desde Europa y Estados Unidos, los diferentes procesos y fenómenos que tienen lugar dentro del campo artístico y en las relaciones que éste establece con la sociedad dentro del contexto latinoamericano. Este punto también indica que una buena parte de los referentes teóricos estudiados hoy, y que constantemente se reproducen, desconocen el aporte de intelectuales e investigadores de nuestro continente.

Por este mismo motivo, y volviendo a la invitación de Canclini de reformularnos las preguntas, se impone un cuestionamiento también medular: ¿Por qué encarar desde la perspectiva de los estudios culturales la contribución de Jorge Mañach a una disciplina de apariencia tan específica como la teoría de la cultura artística? ${ }^{14}$ En este sentido, además de ubicar los antecedentes teóricos y metodológicos, que constriñen el análisis a los estudios filosóficos, literarios, sociológicos o sobre artes, etc., se considera de mayor justeza, el proponer la enunciación de los resortes sobre los cuales un autor como este eleva su propuesta, desde marcos referenciales claramente transdisciplinares, marcados por la tradición electiva del pensamiento cubano.

$\mathrm{Si}$ en efecto, los estudios culturales latinoamericanos, tienen antecedentes de larga data en nuestro continente ${ }^{15}$ los elementos referenciales que sirven para su identificación son: a) reformulación de campos de estudio, b) apertura de objetos de investigación, sin apego exclusivo a métodos, pero c) anclados en la lógica enunciativa del ensayo. Entonces, estamos también en condiciones de incorporar la obra de Jorge Mañach al índice de autores latinoamericanos que se reconocen como iniciadores de los mismos.

Por otra parte, la propia emergencia de la teoría de la cultura artística como disciplina de estudios, así como su desarrollo y evolución epistemológica, demuestran que, en palabras de Juan Acha, esta es "la disciplina dedicada a estudiar el fenómeno estético, mediante los adelantos de todas las ciencias sociales" $(10)^{16}$. Es por ello que,

14 En lo sucesivo se emplearán indistintamente los términos "estudios culturales" y "estudios intelectuales en cultura y poder".

15 Ríos 2002; Mato 2002; Richard 2005; Bueno 2012.

16 Para un estudio más profundo de la evolución de la teoría del arte véase de Arnold Hauser Sociología del arte (1969); de Nicos Hadjinicolau Historia del arte y lucha de clases (1974); de Pedro Mir Fundamentos de teoría y crítica de arte (1979); de Néstor García Canclini La producción simbólica. Teoría y método en sociología del arte (1984); de Estela Ocampo Teorías del arte (1992). 
justo en el punto en el que los estudios sobre la cultura convergen con los dedicados a las diferentes manifestaciones artísticas desde la elucidación teórica, se encuentra un fértil espacio en donde los trazados disciplinares, movidos por lo más lúcido del pensamiento latinoamericano y, en abierto y franco diálogo con su tiempo, tomaron al arte -o en el caso de Mañach, al estilo artístico- como excusa para profundizar en temas como la identidad cultural, la historia, la herencia colonial, la diferencia o el papel del intelectual.

Ahora bien, para el caso particular de América Latina, también Raúl Bueno, en Promesa y descontento de la modernidad (2012), al igual que muchos de los autores tratados anteriormente, propone que los estudios culturales (ee. cc.) latinoamericanos están urgidos de revisar la idea de que las supuestas "reconfiguraciones de campo y objeto" de los mismos se iniciaron en Europa y Estados Unidos.

Tales reconfiguraciones no han sido ajenas a los intelectuales latinoamericanos, sino que se jerarquizan de otra manera (Raúl Bueno). También este autor sugiere, al igual que Ríos, que la tradición de los estudios culturales latinoamericanos tienen una data "que en muchos aspectos anticipan, rebasan, matizan o diversifican los programas batientes de la hora" (126). Sobre esto mismo:

se ha dicho que los ee. cc. rompen barreras epistemológicas y trascienden los campos
de las ciencias humanas y sociales para tratar un ámbito que es, a la vez, común y
ajeno a todas ellas y aún a otras disciplinas: el de la cultura. Yo no creo que haya ahí
realmente una ruptura epistemológica, sino más bien una modificación del campo
y una parcial reformulación del objeto, lo que genera nuevas disciplinas sobre lo
cultural (...) Pero sirva la metáfora de las barreras rotas para poner un énfasis en
la ensayística cultural, que libera al estudioso de los cepos de la argumentación
-los rigores del método y la prueba-y le permite libertades intra- trans- y aun
a-disciplinarias, para tender hipótesis e interpretantes de variado alcance sobre
lo cultural. (128)

En suma, la aceptación de que los estudios culturales latinoamericanos anteceden a los British Cultural Studies, ganan en densidad epistémica y carácter transdisciplinar antes de su legitimación eurocéntrica, nos coloca en un justo ángulo de análisis y exploración de la contribución de intelectuales de nuestro continente en relación con temáticas culturológicas. De modo particular, la relación con la teoría de la cultura artística en Historia y estilo, de Jorge Mañach.

Probablemente, a la no visualización de esta idea se deban las visiones parcializadas acerca de numerosos intelectuales del siglo XX cubano, cuando tratamos de contextualizar nuestros actuales análisis de sus obras, desde miradas ancladas en ciencias o disciplinas que emanan de los claustros académicos: Jorge Mañach, desde la Filosofía, desde la Literatura, desde la Crítica, desde la identidad o la nacionalidad; o en cambio, cuando el análisis resulta de una anticipada parcialización: Jorge Mañach en sus polémicas, en sus debates. 
Otro aspecto que también limita la mejor visualización de los aportes a la teoría de la cultura artística desde los estudios culturales latinoamericanos -y específicamente a partir del objeto de estudio aquí planteado- es la ya ancestral disposición humanista de los estudios sobre arte, que ha provocado una escisión de campos y objetos de estudio. En este sentido, además de la importancia de la Antropología, la Sociología es también una ciencia en la que se ha reconocido con mayor fuerza, a partir de las últimas décadas, la necesidad de un enfoque en el estudio del arte, que descentre el análisis de la unidad artista-obra.

En su obra Sociología de la cultura, Raymond Williams define el objeto y el campo de lo que denomina 'subdisciplina'. Para ello plantea que una buena parte de estos estudios son considerados por muchos como "una convergencia de intereses y métodos" o "un agrupamiento difuso de estudios especializados". Igualmente, en opinión de este autor, una de las problemáticas fundamentales está en el propio concepto de cultura que identifica con un "cajón de sastre", localizado luego de campos de investigación mejor definidos y más fructíferos como religión, educación y conocimiento (Williams, 1994).

Sobre este particular, plantea:

La dificultad del término es por lo tanto obvia, pero puede ser fructíferamente considerada como resultado de tipos anteriores de convergencia de intereses. Podemos distinguir dos tipos principales: a) el que subraya el "espíritu conformador" de un modo de vida global, que se manifiesta en toda la gama de actividades sociales, pero que es más evidente en las actividades "específicamente culturales": el lenguaje, los estilos artísticos, las formas de trabajo intelectual; ${ }^{17} \mathrm{y}$ b) el que destaca "un orden social global", dentro del cual una cultura especificable, por sus estilos artísticos y sus formas de trabajo intelectual, se considera como el producto directo o indirecto de un orden fundamentalmente constituido por otras actividades sociales. (1994)

No obstante, ¿cómo reconocer a Emile Durkheim o Georges Gurtvich en las ideas de Jorge Mañach, si a este último no se le reconoce, hasta hoy, en la larga lista de sociólogos cubanos? Sobre esto último, un autor como Rolando Zamora (§) en su artículo La sociología en Cuba hasta 1959: un panorama (2001), no reconoce la posibilidad de que el nombre de Jorge Mañach pueda inscribirse entre estos autores que él refiere. Puntualiza que:

En este campo todos hacían de todo y la especialización era una quimera. Las fronteras difusas entre los objetos de estudio de la etnología, el folklore, la antropología y la sociología, son aquí mucho más imprecisas por la manera en que ellas han ido desarrollándose en la práctica. [...] Pertenecientes a generaciones diferentes, todos tenían, en mayor o menor medida, algo en común: eran intelectuales que, desde

17 Esta idea de un "espíritu conformador" o "espíritu de época” está presente en la obra de Jorge Mañach. 
profesiones afines, incursionaron en el análisis sociológico de los procesos sociales cubanos; pero no fueron sociólogos en el sentido estricto del término. La falta de dedicación, a tiempo completo, se debía a que una buena parte de su vida activa fue consumida por la política [...] las tareas docentes y otras labores del pensamiento (crítica literaria, periodismo, abogacía). (110-111)

Se considera que la vida y la obra de Jorge Mañach, pueden ser visualizadas desde la perspectiva de una sociología de la cultura, incluso la que toma en consideración la diversidad de tareas a las que se enfrentaban los intelectuales cubanos de la etapa republicana. Lo que pretende la presente investigación no supone, de facto, la inclusión de Mañach en la historia de la sociología cubana, aunque sí refrendar los postulados y anclajes que desde esta ciencia supo tomar -con carácter electivo- para sus análisis de la historia y el estilo artístico en Cuba.

En este sentido, la sociología del arte es también relativamente joven en el panorama disciplinar de las ciencias de la cultura artística. Es importante destacar que la preocupación de la sociología por el arte no fue gratuita ni aleatoria. La idea de la sociedad como objeto de estudio había acompañado a numerosos filósofos desde finales del siglo XVIII y había cobrado fuerza desde el XIX. La Revolución Industrial, la necesidad de mano de obra (antes rural) y la consiguiente complejización de las ciudades y sus estructuras, necesitaba de investigaciones que sirvieran al mismo tiempo para explicar y organizar la vida del hombre en sociedad, como ser social.

Hacia 1950 aparecen dos libros que inauguran una disciplina como reacción frente al formalismo imperante en la teoría de arte y como resultado directo del creciente prestigio que tomaban la Sociología y la Antropología. Varios años después, un autor como Pierre Bourdieu confirmaba en 1990 que "la sociología y el arte no se llevan bien" ( 225) basándose en elementos relacionados con la distancia entre los criterios esteticistas y la metodología de que hasta hoy dispone la Sociología para enfrentar, más que el estudio del campo artístico, a la propia obra de arte.

Es importante aclarar que la obra aquí analizada -Historia y estilo-no es exactamente un volumen dedicado a la sociología del arte. Sin embargo, sí tiene un marcado carácter y vocación sociológicos, no solo por los referentes epistémicos que toma para sus análisis (Spencer, Durkheim, Gurtvich), sino por la propia idea de considerar, a determinados elementos extra-artísticos, como invariantes que igualmente operan sobre la evolución y cambio de los estilos. Tal noción en la década del cuarenta resultaba muy novedosa si se toma en cuenta el marcado carácter formalista de numerosos estudios sobre arte en ese momento ${ }^{18}$.

18 En sentido general, pueden visualizarse cuatro grandes tendencias dentro las cuales se agrupa la mayor parte las corrientes teóricas del arte: las corrientes formalistas, las corrientes iconológicas, las psicológicas y las sociológicas. A grandes rasgos, la mayor parte de los estudiosos de las teorías del arte coinciden en que todo enfoque que centre su atención en el campo artístico y el sistema de relaciones que establece con su contexto, tiene carácter sociológico. Separando así, los que parten del análisis del sujeto creador (psicológicos), los que se centran en la estructura interna de la obra de arte (formalistas) y los que tienen como fin de sus análisis el significado y sentido 
Sobre esto mismo, es importante recordar que Jorge Mañach se vinculó en más de una ocasión con importantes universidades de los Estados Unidos y Francia. No es vano tomar en consideración estos elementos que además se perciben con relativa claridad en toda su obra. La idea evolucionista de Herbert Spencer, el análisis de la sociedad de Emile Durkheim, el imperativo temporal del tiempo largo para el estudio del comportamiento de un proceso (que más tarde sería el punto focal de la renovación de los estudios historiográficos en Europa), y la noción de un "espíritu de época" que Georges Gurtvich (con antecedentes directos en la obra de Herder, Taine y Scheler) concentra para el estudio del arte. Todo esto, sin descuidar el aspecto formal del discurso, sostenido por el modelo de ensayo cultural, como se ha apuntado ya, de sólida tradición en América latina.

En atención a esta última idea, el estudio que aquí se propone no necesariamente está sustentado en la idea de un sistema teórico en cuyo interior sean claramente discernibles criterios como conceptos, proposiciones, hipótesis, leyes y paradigmas. Esta noción, también impuesta por la dominante hegemónica del pensamiento europeo, sostiene como el fin último de las disquisiciones de una disciplina, la construcción de un sistema teórico estructuralmente determinado por la lógica antes descrita.

Sin embargo, no se considera que esta sea la única vía metodológica para exponer los aportes de orden teórico. Considérese que en los estudios culturales latinoamericanos, la lógica del pensamiento académico y científico no necesariamente está constreñida por un marco formal (tesis, tratado o artículo científico) en el que se coloque como una invariante el secular esquema planteado desde la lógica aristotélica. Igualmente, el empleo de determinado sistema conceptual y/o categorial no se sirve de normativas semánticas y estilísticas, que supuestamente constituyen la vía expedita para la exposición de ideas en los predios académicos.

Coincidimos con el Dr. Rigoberto Pupo quien defiende la pluralidad de modos literarios para expresar el conocimiento, en oposición a una idea de pares contrapuestos: claustro metodológico vs. libertad metafórica.

El lenguaje directo y tropológico como formas aprehensivas de la realidad por el hombre, son inmanentes al quehacer filosófico y al discurso que lo encauza y lo expresa. No es posible continuar haciendo de la tropología un terreno "vedado" al saber filosófico. La narratividad, la metaforización son modos culturales de asimilación de la realidad por el hombre, y con ello, medios insustituibles de la filosofía. ¿Cuánta filosofía hay en una novela que penetre en la naturaleza humana y sea capaz de pensar su subjetividad y la objetividad con sentido cultural? ¿Es posible negar el numen filosófico a la poesía "que ve con las palabras y habla con los colores" para denotar la humanidad del hombre en su fuerza y fragilidad? ¿Por qué fragmentar la realidad y convertir el

de la obra de arte en cada contexto (iconológicos). Se reconoce que el despegue de las teorías del arte de carácter sociológico ocurre desde fines de la década del cuarenta y principios del cincuenta, aunque tuvieron importantes antecedentes en Hyppolyte Taine, Gueorgi Plejanov, Jean Marie Guyau y Charles Lalo. (Estela Ocampo, 1991) 
género ensayístico en "propiedad privada" de la literatura, cuando su misma esencia y propósitos, dan cuenta de su elan filosófico? (Rigoberto Pupo, 2009: 117)

Sobre esto último, Nelly Richard sostiene que la actual hegemonía académica de los llamados países centrales ha trastocado la larga tradición ensayística de nuestro continente cuando demanda, por ejemplo, normas de presentación de resultados científicos que constriñen sobremanera la libertad retórica de aquel género:

Sin embargo, dicho tema es generalmente desatendido por los estudios culturales cuyo standard académico tiende a producir una suma uniforme de materiales investigativos -regidos por la operatividad tecnocultural del dato- que encuentra su símbolo desapasionado en el paper. La reducción funcionaria del Texto al paper ha roto el emblema de una densa tradición ensayística con el nuevo predominio de la investigación sociológica que sacrifica la espesura retórica y figurativa del lenguaje. (Campos cruzados 203) ${ }^{19}$

Es por ello que se puede visualizar en la metáfora mañachsiana de "agregado amorfo" (de suyo sincrónica y diacrónica) un análisis profundo de la cultura cubana que sirve, a los efectos de un volumen en el que se analiza el estilo, para contextualizar debidamente la evolución de este en un momento dado, sus causas y condicionantes. Precisamente, con el empleo del ensayo como género literario, más que tradición, sirve como soporte, con el uso de recursos que trascienden y distinguen al pensamiento cubano desde su obra, sin que ello suponga alguna limitación de tipo conceptual, epistémica y/o metodológica para su momento.

Tómese en cuenta que la intención de los Cultural Studies (británicos) y los desarrollados en Latinoamérica, como bien han señalado Yúdice, Ríos y Bueno, emergieron desde el desplazamiento de los límites entre campos, objetos y disciplinas de estudio, y al mismo tiempo, marcados por profundos nacionalismos. Aunque, como se ha apuntado, los estudios culturales latinoamericanos tienen su fecha de nacimiento en el siglo decimonónico.

Precisamente, sobre la tradición culturalista a la que pertenece el texto objeto de estudio, en relación a la obra de Mañach, Rigoberto Segreo, en Más allá del mito. Jorge Mañach y la Revolución cubana (2012) refiere que:

Además de su expresión en el campo económico y político, el nacionalismo de Jorge Mañach cobra cuerpo en lo cultural, que acabará fundiéndose con los dos anteriores. Acaso sea en ese plano donde más productivo se hace. Su centro estriba en la concepción de una teoría cultural orgánica, que lejos de atomizar sus componentes, los asume como una unidad coherentemente estructurada. (76)

19 Cursivas y mayúscula de la autora. 
Razón de peso para pormenorizar, en aras de lograr un mejor estudio en términos metodológicos, los referentes presentes en Historia y estilo, su empleo, vínculo con zonas afines y actualidad del mismo. Es en este sentido, y debido a su ubicación cronológica en la producción total (en vida del autor) se escoge este volumen, también en vistas del paradigma cualitativo sobre el que se sostiene la presente indagación; o sea, la investigación en profundidad, más que la extensión. Particularmente, si nos proponemos adentrarnos en la densidad teórica de esta obra de 1944, en la que la preocupación por el estilo está constantemente intersecada por cuestiones como la nacionalidad, el tránsito vanguardista, la identidad, la invariante histórica sobre el estilo, entre otras.

La investigación cualitativa de la cultura y el arte en general emprende estudios en pequeña escala, de manera que se analicen intensivamente unos pocos casos. En la investigación del arte, cuando se enfoca una obra, conjunto de obras, un movimiento artístico, se trata de fenómenos sui generis, en el sentido de que son irrepetibles, y constituyen una fuente de investigación que probablemente no se pueda abordar mediante métodos cuantitativos. (Álvarez y Barreto, El arte de investigar el arte)

De cualquier modo, el acercamiento a tal volumen, deberá realizarse desde una correcta visualización de aspectos inherentes a su autor y al ensayismo mañachiano. Algunos de estos son expresión directa de la pertenencia de Jorge Mañach a la tradición electivista del pensamiento cubano, o en caso contrario, el síntoma evidente del diálogo actualizado de este autor con sus contemporáneos, sin que se pueda ya desconocer su pertenencia a la larga tradición de los estudios culturales latinoamericanos.

\section{Referencias}

Acha, Juan. Las culturas estéticas de América Latina. México: UNAM, 1993.Medio impreso.

Álvarez, Luis y Gaspar Barreto. El arte de investigar el arte. Colección Diálogo. Santiago de Cuba: Oriente, 2010. Medio impreso.

Arcos, Jorge Luis. "Prólogo" en Ensayos Jorge Mañach. La Habana: Letras Cubanas, 1999. Medio impreso.

Bourdieu, Pierre. Sociología y cultura. México: Grijalbo, 1990. Medio impreso.

Bueno, Raúl. Promesa y descontento de la modernidad. Premio de ensayo Ezequiel Martínez Estrada. La Habana: Fondo Editorial Casa de las Américas, 2012. Medio impreso.

Colombres, Adolfo. América como civilización emergente. Buenos Aires: Sudamericana, 2004. Medio impreso.

Díaz Infante, Duanel. Mañach o la República. La Habana: Letras Cubanas, 2003. Medio impreso. 
Fernández Retamar, Roberto. Para una teoría de la literatura hispanoamericana. La Habana. Cuadernos Casa, 1979. Medio impreso.

García Canclini, Néstor. La Producción Simbólica. Teoría y Método en Sociología del Arte. México. Siglo XXI, 1984. Medio impreso.

---. "Memory and Innovation in the Theory of Art" Postmodernism: Center and Periphery. Revista The South Atlantic Quarterly SAQ. Volume 92, Number 3.

Duke University Press, 1993. 423-443. Medio impreso.

Hadjinicolau, Nicos. Historia del arte y lucha de clases. México: Siglo XXI, 1974.

Medio impreso.

Hauser, Arnold. Introducción a la Historia del Arte. La Habana: Instituto del Libro, 1969. Medio impreso.

Jameson, Frederic. "Introduction" en Postmodernism: Center and Periphery. Revista The South Atlantic Quarterly SAQ. Volume 92, Number 3. Duke University Press, 1993. 417-422. Medio impreso.

Mañach, Jorge. Martí,el apóstol. Madrid: Espasa-Calpe, 1933. Medio impreso.

---. Historia y estilo. La Habana:Minerva, 1944. Medio impreso.

---. Para una filosofía de la vida y otros ensayos. La Habana. Editorial Lex, 1951. Medio impreso.

---. Paisaje y pintura en Cuba. Madrid: Artes Gráficas Ibarra, 1959. Medio impreso. ---. Dewey y el pensamiento Americano. Madrid: Taurus, 1959. Medio impreso.

Mato, Daniel (Comp.). Estudios y otras prácticas intelectuales latinoamericanas en cultura y poder. Caracas: CLACSO y CEAP, FACES, Universidad Central de Venezuela, 2002. Medio impreso.

Mir, Pedro. Fundamentos de teoría y crítica de arte. Santo Domingo: Publicaciones de la Universidad Autónoma de Santo Domingo, Volumen CCLXVI, 1979. Medio impreso.

Mosquera, Gerardo. "Robando del pastel global. Globalización, diferencia y apropiación cultural" en Horizontes del arte latinoamericano (José Jiménez y Fernando Castro, Editores). Madrid: Tecnos, 1999. Medio impreso.

Ocampo, Estela y Martí Peran. Teorías del arte. Madrid: Siglo XXI, 1992. Medio impreso. Pupo Pupo, Rigoberto. El hombre, la actividad humana, la cultura y sus mediaciones fundamentales. Presentación de resultados en opción al grado científico de Doctor en Ciencias. Universidad de La Habana, 2006. Medio impreso.

Richard, Nelly. La estratificación de los márgenes. Santiago: Francisco Zegers, 1989. Medio impreso.

---. "Saberes académicos y reflexión crítica en América Latina" en Estudios y otras prácticas latinoamericanas en Cultura y Poder (Coord. Daniel Mato). Caracas: CLACSO y CEAP, FACES, Universidad Central de Venezuela, 2002. Medio impreso.

---. Campos cruzados. Crítica cultural, latinoamericanismo y saberes al borde en Cuadernos Casa N 44. La Habana: Casa de las Américas, 2003. Medio impreso. 
---. “Globalización académica, estudios culturales y crítica latinoamericana” en Cultura, política y sociedad. Perspectivas latinoamericanas (Coord. Daniel Mato). Buenos Aires. Consejo Latinoamericano de Ciencias Sociales CLACSO, 2005. Medio impreso.

Ríos, Alicia. "Los Estudios Culturales y el estudio de la cultura en América Latina" en Estudios y otras prácticas latinoamericanas en Cultura y Poder (Coord. Daniel Mato). Caracas: CLACSO y CEAP, FACES, Universidad Central de Venezuela, 2002. Medio impreso.

Rojas, Rafael. Motivos de Anteo. Patria y Nación en la historia intelectual de Cuba. España: Colibrí, 2008. Medio impreso.

Sarlo, Beatriz. "Los estudios culturales y la crítica literaria en la encrucijada valorativa" en Crítica cultural No 15 (noviembre). Santiago, 1997. 32-38. Medio impreso.

Segreo, Rigoberto. “Vanguardismo y antivanguardismo en Jorge Mañach” Premio Temas de Ensayo 2011, en Temas Nº70 (abril-junio). La Habana, 2012. 93-101. Medio impreso.

Segreo, Rigoberto y Margarita Segura. Más allá del mito. Jorge Mañach y la Revolución cubana. Santiago de Cuba: Oriente, 2012. Medio impreso.

Torre, Amalia de la. Mañach, maestro del ensayo. Miami: Universal, 1978. Medio impreso.

Valdespino, Andrés. "Jorge Mañach y su contribución a la cultura hispanoamericana" en revista La Torre $\mathrm{N}^{\circ} 68$ (abril-junio). Puerto Rico, 1960. Medio impreso.

Willimas, Raymond. Sociología de la cultura. Madrid: Paidós, 1994. Medio impreso.

Yúdice, George. "Contrapunteo estadounidense/latinoamericano de los estudios culturales" en Estudios y otras prácticas latinoamericanas en Cultura y Poder (Coord. Daniel Mato). Caracas: CLACSO y CEAP, FACES, Universidad Central de Venezuela, 2002. Medio impreso.

---. El recurso de la cultura. Usos de la cultura en la era global. La Habana: Ciencias Sociales, 2006. Medio impreso.

Zamora, Rolando. "La sociología en Cuba hasta 1959: un panorama” en Temas N²425 (enero-junio). La Habana, 2001. 109-122. Medio impreso.

Recibido: 28 noviembre 2013 Aceptado: 02 abril 2014 